\title{
La detección antígeno-específica de linfocitos $T$ y sus aplicaciones clínicas
}

\author{
Alexis M Kalergis $\mathrm{P}^{1 a}$, Alberto Fierro ${ }^{2}$, Claudio Figueroa $\mathrm{G}^{1 \mathrm{c}}$, \\ Pablo G onzález $\mathrm{M}^{1 \mathrm{~d}}$, Jaime Tobar $\mathrm{R}^{1 \mathrm{~b}}$. \\ Clinical applications of antigen- \\ specific detection of T lymphocytes
}

The important role that $\mathrm{T}$ lymphocytes play during the immune response against pathogens and tumor cells has encouraged the development of technologies aimed to detect these immune cells in an antigen-specific fashion. Recently, a methodology consisting of the production of soluble ligands that bind the $\mathrm{T}$ lymphocyte receptor was developed. Such ligands consist of molecules from the Major Histocompatibility Complex loaded with either pathogen or tumor derived peptides. These molecular complexes are tetramerized to enhance the binding efficiency to the T cell receptor (TCR), which improves the detection sensitivity of antigen specific T lymphocytes. This new technology is currently used successfully during the follow up patients that were vaccinated against certain tumor antigens, to evaluate the expansion of tumor specific T lymphocytes. This methodology is also promising for the detection and specific deletion of autoreactive T lymphocytes as a treatment for autoimmune disorders. In this article we review the molecular components involved in antigen recognition by T lymphocytes, and the potential benefits for Biomedicine that could result from the detection of these cells by soluble specific ligands (Rev Méd Chile 2004; 132: 371-80).

(Key Words: Histocompatibility antigens; Immunity, cellular; T Lymphocytes)

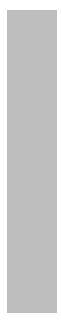

\footnotetext{
Recibido el 19 de junio, 2003. Aceptado en versión corregida el 6 de enero, 2004.

Trabajo financiado por proyecto FONDECYT \#1030557.

${ }^{1}$ Unidad de Inmunogenética Molecular. Laboratorio de Microbiología. Departamento de Genética Molecular y Microbiología. Facultad de Ciencias Biológicas, Pontificia Universidad Católica de Chile. ${ }^{2}$ Unidad de Trasplante y Nefrología, Clínica Las Condes. aBioquímico, Doctor en Microbiología e Inmunología.

bBiólogo, estudiante de Doctorado en Genética Molecular y Microbiología.

'Bioquímico, estudiante de Doctorado en Genética Molecular y Microbiología.

dEstudiante-tesista de Bioquímica.
}

Correspondencia a: Dr. Alexis Kalergis. Departamento de Genética Molecular y Microbiología. Facultad de Ciencias Biológicas, Pontificia Universidad Católica de Chile. Alameda 340 (Casilla 1114-D), Santiago, Chile. Fono: 562-6862842. E mail: kalergis@genes.bio.puc.cl. 
$\mathrm{E}^{\mathrm{n}}$ los últimos años, los esfuerzos y recursos invertidos en investigación básica en el área de las interacciones moleculares entre el sistema inmune de un hospedero animal y agentes patógenos o células tumorales, ha aumentado significativamente en países desarrollados. Dado al inesperado incremento de cepas de patógenos resistentes a los antibióticos disponibles en la actualidad, como también de tumores metastásicos que resisten la quimio y radioterapia, esta área de investigación se ha hecho prioritaria para las organizaciones que financian la ciencia.

Por la problemática que representa la resistencia de los agentes patógenos a las actuales metodologías, el estudio para el desarrollo de nuevas terapias se ha enfocado principalmente en promover una respuesta inmune activa por parte del hospedero, que asegure la eliminación efectiva de tumores y patógenos. La potencial eficacia del sistema inmune en la ejecución de esta tarea, queda demostrada por el extenso número de estrategias moleculares que los agentes patógenos y las células tumorales han desarrollado para evadirlo $^{1-4}$. En este aspecto, la forma en que el sistema inmune interacciona física y molecularmente con el agente patógeno o la célula tumoral, es fundamental para determinar el tipo de respuesta que se montará contra estos agentes y el entendimiento de las interacciones moleculares en el sistema inmune, es de vital importancia para el desarrollo de estrategias de eliminación efectivas de estos agentes peligrosos para el organismo.

Dentro del sistema inmune del hospedero, un tipo de células denominadas linfocitos $\mathrm{T}$ (por su desarrollo en el timo) juega un papel fundamental en la orquestación y ejecución de la respuesta inmune. Una de las evidencias más sólidas para proponer que los linfocitos $\mathrm{T}$ juegan un papel crítico en la respuesta a agentes, tales como bacterias patógenas y células tumorales, proviene de animales que han sido hechos genéticamente deficientes de linfocitos $\mathrm{T}$, los que presentan una alta susceptibilidad a infecciones bacterianas y son incapaces de prevenir el crecimiento de tumores ${ }^{5-7}$. Estas observaciones en modelos animales son extrapolables a humanos, ya que en individuos con deficiencias en linfocitos $\mathrm{T}$ presentan cuadros patológicos similares a los observados en estos animales genéticamente modificados ${ }^{8,9}$.
Las interacciones moleculares entre la célula presentadora de antígeno (APC) y los linfocitos T, son fundamentales para la eliminación efectiva de células infectadas con bacterias, como también de células tumorales. La activación del linfocito $\mathrm{T}$ es gatillada por el reconocimiento específico de antígenos presentados en forma de complejos péptido-MHC (pMHC) en la superficie de la APC por parte del receptor de linfocito T (TCR) (Figura 1). La especificidad de la interacción entre el TCR $\mathrm{y}$ el $\mathrm{pMHC}$ es fundamental para asegurar una respuesta inmune dirigida exclusivamente hacia antígenos exógenos, y evitar así una respuesta autoinmune hacia moléculas propias del hospede$\mathrm{ro}^{10,11 .}$

Una vez que linfocitos $\mathrm{T}$ con receptores específicos para un complejo pMHC en particular han sido activados, éstos proliferan en el animal a través de un proceso denominado expansión clonal $^{10,11}$. Hasta no hace mucho, la detección de estos clones de linfocitos $\mathrm{T}$ específicos solamente era posible mediante técnicas de cultivo, en las que células provenientes de la sangre $u$ otros tejidos eran cultivadas en presencia del antígeno. Luego de varios días, la presencia en el cultivo de linfocitos T específicos para el antígeno de interés era evaluada mediante ensayos biológicos de proliferación o secreción de citoquinas. Esta estrategia, además de ser costosa y muy laboriosa, sólo permite un análisis cualitativo de los linfocitos $\mathrm{T}, \mathrm{y}$ no permite la cuantificación de linfocitos $\mathrm{T}$ antígeno-específicos dentro de la población total de linfocitos del individuo o animal estudiado.

La baja afinidad intrínseca del TCR por el complejo pMHC fue un impedimento para la detección directa de linfocitos $\mathrm{T}$ mediante complejos pMHC solubles de forma monomérica, marcados ya sea radiactiva o fluorométricamente $\mathrm{t}^{11-14}$. Sin embargo, recientemente ha sido desarrollada una nueva metodología para la detección de linfocitos $\mathrm{T}$ antígeno-específicos. Esta consiste en la producción, mediante técnicas de ADN recombinante, de moléculas de pMHC solubles, las cuales pueden ser tetramerizadas por una serie de reacciones químicas. Producto de un aumento en la avidez, la tetramerización de los complejos pMHC se sobrepone a la baja afinidad de la interacción TCR:pMHC y permite la detección de aquellos linfocitos $\mathrm{T}$ que presentan en su superfi- 


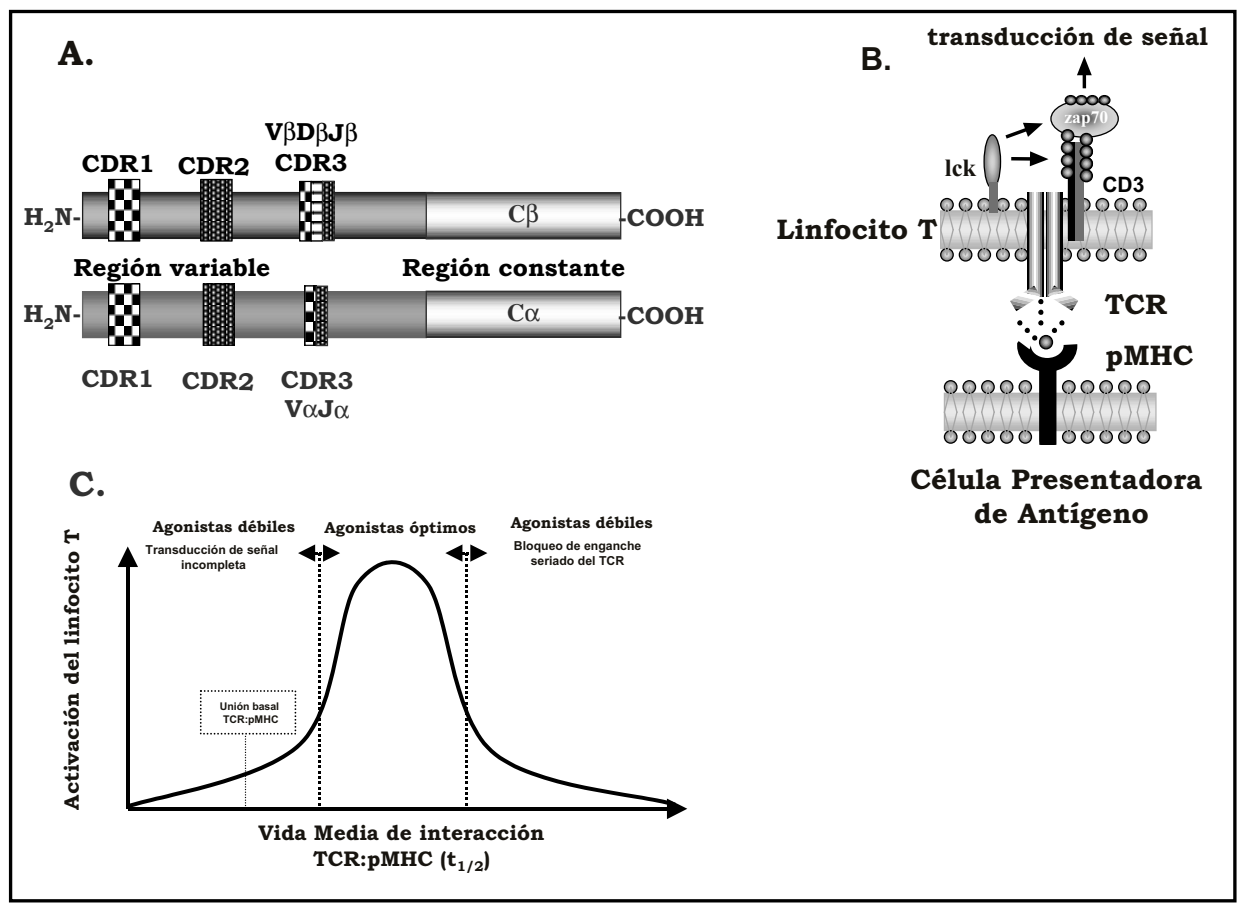

FiguRa 1. Estructura y función del receptor del linfocito T (TCR). A. Esquema de la estructura TCR: es una proteína heterodimérica y se compone de una cadena $\alpha$ y una $ß$. Cada cadena tiene una región constante (transmembrana) y una variable. Esta última contiene 3 regiones de alta diversidad (regiones determinantes de la complementariedad, o CDR 1, 2 y 3) las cuales definen el sitio de unión al antígeno, o pMHC. B. Estructura cristalina del complejo molecular TCR-pMHC en la interfase entre el linfocito T y la célula presentadora de antígeno. Mientras la estructura del complejo TCR-pMHC del humano fue resuelta por el grupo de Don Wiley ${ }^{58}$, la del ratón fue resuelta por el grupo de Ian Wilson ${ }^{59,60}$. C. Modelo para la activación del linfocito T en relación a la vida media (t1/2) de interacción entre el TCR y el pMHC ${ }^{12,22}$. La activación óptima del linfocito T ocurre sólo dentro de un rango de vida media de interacción TCR:pMHC.

cie TCRs específicos para un complejo pMHC en particular ${ }^{10,15-18}$. En este artículo se discutirán las bases moleculares de la interacción entre el TCR y el complejo pMHC, la detección in vivo de linfocitos $\mathrm{T}$ específicos mediante tetrámeros de pMHC y sus aplicaciones a la biomedicina.

\section{LA INTERACCIÓN TCR:PMHC Y LA ACTIVACIÓN DEL LINFOCITO T}

El TCR es una proteína de membrana heterodimérica de tipo I que presenta una enorme diversidad, la que está compuesta de dos subunidades, una cadena $\alpha$ y una $\beta$, las cuales se asocian mediante puentes disulfuro (Figura 1A). Cada cadena contie- ne una región constante (proximal a la membrana del linfocito T) y una variable (distal de la membrana) ${ }^{10-13,19}$, siendo esta última la que contiene el sitio de unión al ligando pMHC. La especificidad de cada TCR está determinada por 3 secuencias hipervariables, denominadas regiones determinantes de la complementariedad (CDR 1, 2 y 3), presentes en la región variable de las cadenas $\alpha$ y ß. Mientras la diversidad de las regiones CDR1 y CDR2 está limitada por el número de genes para V $\alpha$ o Vß (alrededor de 100 en el ser humano), la diversidad de las regiones CDR3 resulta de procesos de recombinación somática que ocurren durante el desarrollo de cada linfocito $\mathrm{T}^{20}$. Se ha calculado que el número potencial de posibles combinaciones en la estructura del TCR podría 
llegar a ser alrededor de $10^{15}$, lo que proporcionaría un repertorio lo suficientemente abundante de receptores para reconocer el vasto universo de antígenos presentes en el ambiente ${ }^{10-13}$. Debido a que la región constante posee un segmento intracelular demasiado corto para transducir señal, ésta se asocia con moléculas accesorias denominadas CD3

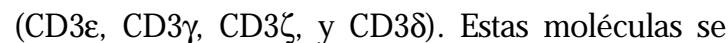
especializan en la transducción de señal al interior del linfocito $\mathrm{T}$, una vez que el TCR ha interactuado con el complejo pMHC para el cual es específiCo $^{11,12,14,19}$.

El complejo pMHC, que es el ligando del TCR, está compuesto por péptidos pequeños derivados de proteínas antigénicas, los que se asocian con las moléculas del complejo mayor de histocompatibilidad $(\mathrm{MHC})^{12,21}$. Estas moléculas de MHC se especializan en la función de presentar tales péptidos antigénicos a los linfocitos T (Figura 1B). Existen dos tipos de moléculas de MHC denominadas de clase 1 (MHC-I) y de clase 2 (MHC-II), las que cumplen roles diferentes en la presentación de antígenos al sistema inmune. Mientras las moléculas MHC-I presentan péptidos antigénicos a linfocitos $\mathrm{T} C D 8^{+}$citotóxicos, los MHC-II lo hacen a linfocitos T $\mathrm{CD} 4^{+}$ayudadores. En general, los péptidos que son presentados en MHC-I provienen de proteínas intracelulares, ya sea del citoplasma de la célula del hospedero, o de un patógeno intracelular (viral o bacteriano) mientras que los péptidos presentados en las moléculas de MHC-II provienen en su mayońa de proteínas extracelulares, ya sea solubles del espacio intersticial o de patógenos extracelulares ${ }^{11}$.

Cuando un complejo pMHC en la superficie de la APC es reconocido por un TCR específico (Figura 1B), el linfocito $\mathrm{T}$ es activado, prolifera y expresa funciones efectoras tales como secreción de citoquinas y, en el caso de los $\mathrm{CD}^{+}{ }^{+}$, actividad citotóxica. Para evitar autoinmunidad, la activación del linfocito $\mathrm{T}$ debe estar estrictamente regulada y limitada al reconocimiento de péptidos extraños unidos al MHC.

La interacción TCR-pMHC es de baja afinidad $\left(\mathrm{Kd} \approx 10^{-6} \mathrm{M}\right)$, la cual se mantiene relativamente en el mismo rango, sin presentar un aumento significativo durante el desarrollo de la respuesta inmune, independientemente del número de inmunizaciones. Recientemente, se ha demostrado que para que el linfocito $\mathrm{T}$ sea activado, la interacción TCR-pMHC debe estar dentro de un rango de afinidad específico ${ }^{22}$ (Figura 1C). Interacciones de afinidad muy baja o muy alta no permiten la activación del linfocito $\mathrm{T}^{22}$, lo que explicaría la existencia de un umbral de afinidad, sobre el cual deben estar los linfocitos $\mathrm{T}$ para ser activados, como también la ausencia de un incremento de afinidad de los linfocitos $\mathrm{T}$ durante la respuesta inmune ${ }^{12,13}$ (Figura 1C). Esta característica permite al sistema inmune seleccionar a la población $\mathrm{T}$, tanto por su especificidad como por sus propiedades de unión al antígeno presentado en el contexto de las moléculas de MHC.

\section{DETECCIÓN ESPECÍFICA DE LINFOCITOS T MEDIANTE TETRÁMEROS DE PMHC}

La baja afinidad intrínseca de la interacción TCR-pMHC había dificultado la detección de linfocitos T específicos para un antígeno en particular mediante complejos pMHC recombinantes monoméricos ${ }^{11-13,15}$. La velocidad de disociación de tales ligandos monoménicos, es demasiado rápida para permitir la detección de TCR específicos utilizando $\mathrm{pMHC}$ marcados radiactivamente o con fluorocromos ${ }^{12,18}$. A fin de superar el problema de la baja afinidad del TCR por su ligando, se ha desarrollado una técnica que tiene por objetivo aumentar la avidez de la interacción TCR-pMHC, mediante la multimerización (tetramenización) de complejos pMHC idénticos ${ }^{16,17}$. A fin de inducir la tetramerización de complejos de pMHC, una molécula única de biotina es incorporada, ya sea enzimáticamente ${ }^{17} 0$ químicamente $^{16}$, en el extremo carboxilo-terminal de la molécula de MHC (Figura 2). Al estar localizada en el C-terminal del MHC, la molécula de biotina no interfiere con el sitio de unión al TCR, el cual se halla en el extremo amino-terminal del MHC. Los complejos pMHC así biotinilados, se combinan con estreptavidina, una proteína tetramérica derivada del estreptococo, compuesta de cuatro subunidades idénticas, cada una de afinidad muy alta $\left(\mathrm{Kd} \approx 10^{-13} \mathrm{M}\right)$ por una molécula de biotina. Estas propiedades químicas y estructurales de la estreptavidina, permiten la tetramerización de 4 complejos de pMHC biotinilados. La ubicación de la biotina en el C-terminal de la molécula de MHC permite orientar cada complejo pMHC correctamente para unirse al TCR ${ }^{16}$.

Esta estrategia aumenta la estabilidad de la unión de los complejos pMHC a la superficie de linfocitos $\mathrm{T}$, que poseen un TCR específico para el mismo 


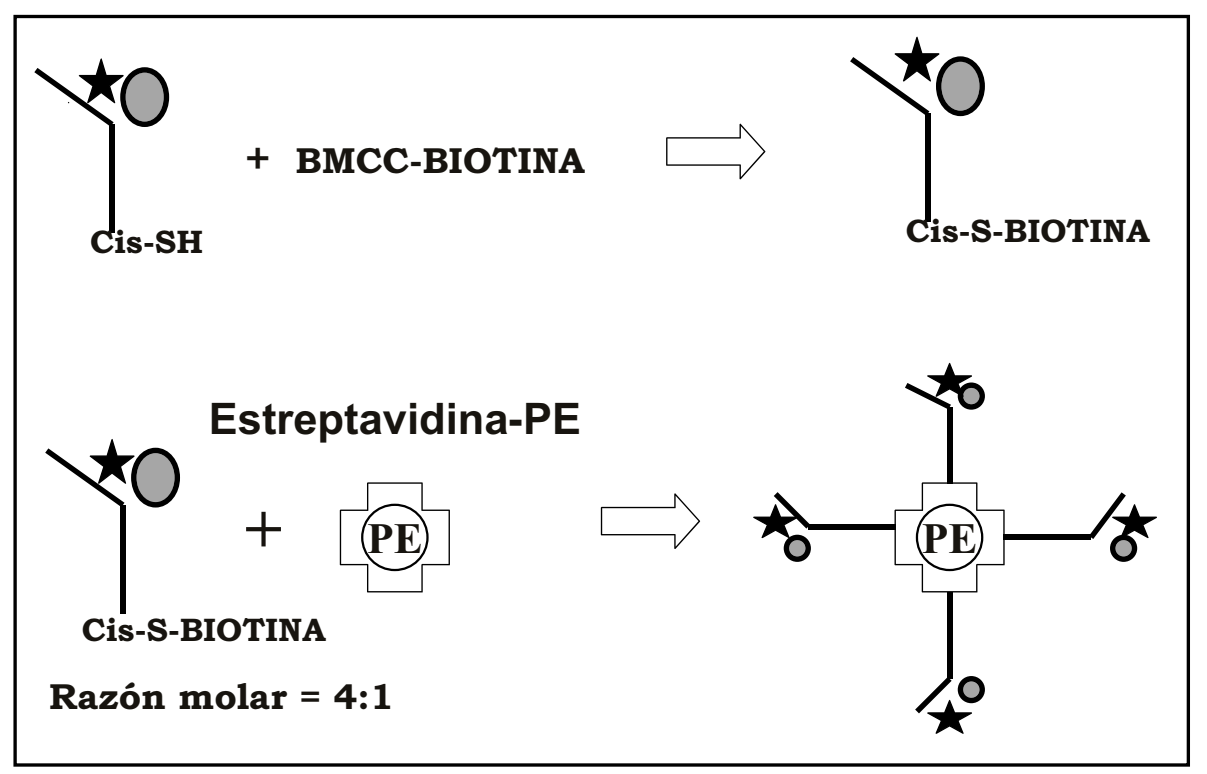

FIgURA 2. Metodología para el diseño de tetrámeros de pMHC. Los complejos de pMHC (cadena pesada MHC + péptido + ß2-microglobulina) son obtenidos mediante expresión en bacterias recombinantes, el ensamblaje es realizado mediante diálisis y la purificación por técnicas cromatográficas ${ }^{16}$. Estos complejos de pMHC contienen un residuo de cisteína libre en el extremo carboxilo terminal, el cual puede ser biotinilado químicamente con BMCC. La tetramerización se logra mediante la combinación de complejos pMHC biotinilados con estreptavidina, molécula que posee cuatro sitios de unión para la biotina. Esta reacción se lleva a cabo en condiciones de exceso molar de complejos pMHC biotinilados a fin de saturar los sitios de unión en la estreptavidina lo que asegura la obtención de tetrámeros. Los tetrámeros de pMHC son separados y purificados del exceso de pMHC monoméricos mediante cromatografía de exclusión molecular ${ }^{16}$. Las moléculas de estreptavidina pueden estar marcadas con fluorocromos tales como isothiocianato de fluoresceína (FITC, fluorescencia verde) o ficoeritrina (PE, fluorescencia roja) lo que permite la detección de la unión de los tetrámeros a linfocitos T mediante citofluorometría.

pMHC. Como resultado de una unión más estable, la presencia de pMHC en la superficie del linfocito $\mathrm{T}$ puede ahora ser detectada mediante técnicas como citofluorometría de flujo ${ }^{16,18}$ (Figura 3).

\section{APLICACIONES CLÍNICAS DE LOS TETRÁMEROS DE PMHC}

Tumores. Debido al aumento de la afinidad en la unión al TCR, los tetrámeros poseen un gran potencial en el área del diagnóstico clínico. Una de las aplicaciones con más relevancia de los tetrámeros de pMHC en la medicina humana ha sido la evaluación de la efectividad de vacunas tumorales 23,24 . Este tipo de vacunas basa su acción en el hecho que las células tumorales expresan antígenos que no son encontrados en células normales, lo que el sistema inmune reconoce como extraño y es señal para su eliminación por la población linfocitaria T CD8 ${ }^{+}$. La detección con tetrámeros de linfocitos T citotóxicos que son específicos para antígenos tumorales y que se han expandido luego de la vacunación, está asociada con un pronóstico positivo en pacientes con cáncer, ya que un aumento en el número de linfocitos $\mathrm{T}$ citotóxicos específicos implica un progreso por parte del sistema inmune en el proceso de eliminación de los tumores que expresan tales antígenos ${ }^{23-25}$. El seguimiento con tetrámeros de pMHC, en pacientes con cáncer que han sido vacunados con una variedad de formulaciones para vacunas antitumorales, se está comenzando a practicar en hospitales extranjeros asociados a centros de investigación biomédica ${ }^{26-}$ 


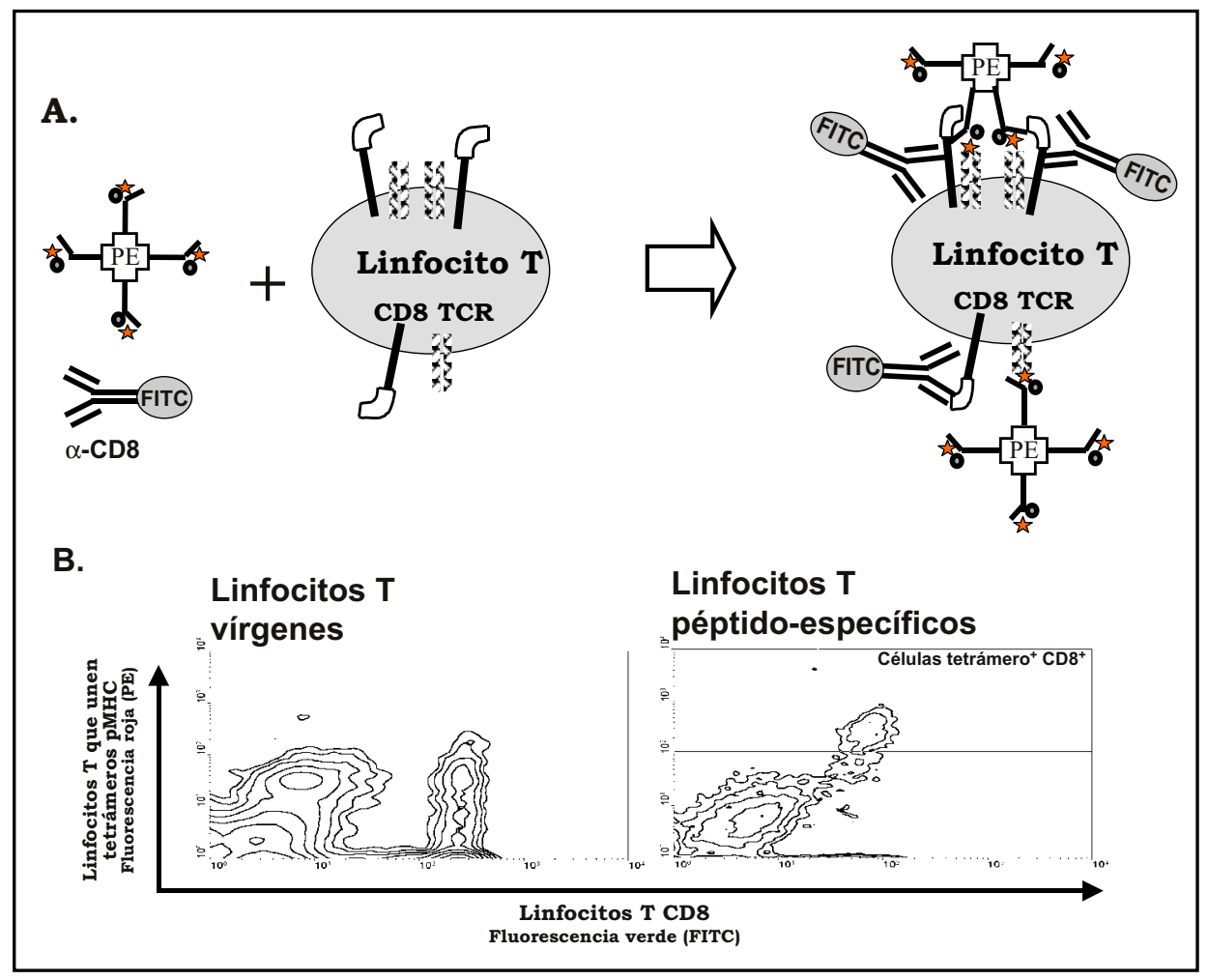

FIgURA 3. Detección de linfocitos T antígeno-específicos con tetrámeros de pMHC. A. La unión de los tetrámeros a los linfocitos T ocurre sólo cuando éstos tienen en su superficie receptores (TCRs) específicos para el complejo pMHC presente en los tetrámeros. La detección se realiza utilizando simultáneamente un marcador de superficie para identificar la población de linfocitos T específica (en este caso linfocitos T CD ${ }^{+}$) y los tetrámeros de pMHC. B. El análisis citofluorimétrico demuestra la aparición de una población positiva para los complejos pMHC tetraméricos sólo en individuos que han generado eficientemente una respuesta inmune antígeno específica. Esta interpretación resulta de la observación de una población de células doblemente positiva para CD8 y tetrámeros pMHC en el cuadrante superior derecho del gráfico, la cual no se observa antes de que se haya generado la respuesta inmune específica.

34. Sin embargo, existe cierta controversia respecto a que exista una correlación estricta entre la unión de los tetrámeros a linfocitos T citotóxicos y la capacidad de éstos de ser activados por antígenos presentados por células tumorales $22,23,25$.

Enfermedades infecciosas. En enfermedades infecciosas, especialmente de tipo viral, los tetrámeros se han empezado a utilizar como metodología para el diagnóstico y el monitoreo de la evolución de patologías infecciosas, como en hepatitis $\mathrm{C}$, citomegalovirus y VIH ${ }^{35-39}$. El uso de tetrámeros ha permitido que, mediante muestras de sangre, periférica se puedan obtener resultados sobre el desarrollo de la enfermedad y conocer cómo responden los individuos en estudio a las terapias contra los agentes infecciosos en cuestión, ya que al igual que en el caso de vacunas tumorales, un aumento de la población específica de linfocitos T $\mathrm{CD} 8^{+}$contra el agente viral, significa una respuesta positiva del sistema ante el agente infeccioso. Aunque sólo se han obtenido resultados preliminares, las expectativas para este tipo de metodologías en el área de patologías infecciosas son muy prometedoras.

Autoinmunidad. Otro tipo de enfermedades donde el uso de los tetrámeros tiene un gran campo de 


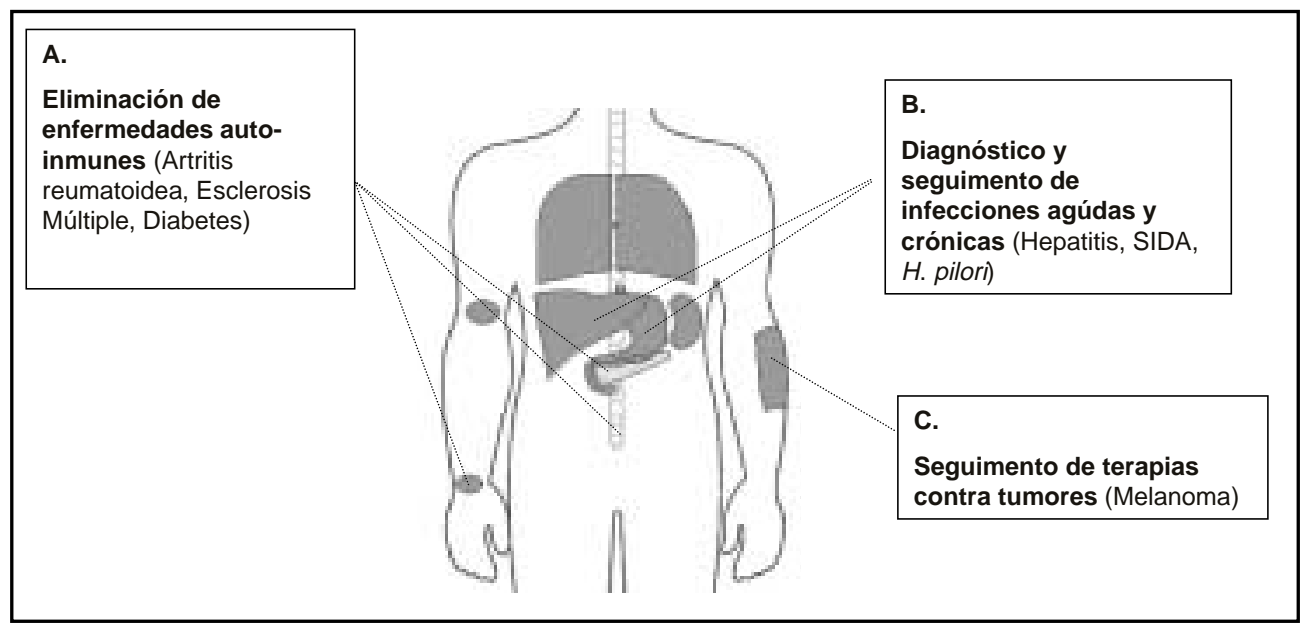

FIgURA 4. Aplicaciones biomédicas de la detección de linfocitos T. La detección de linfocitos T mediante el uso de tetrámeros cargados con péptidos específicos podría ser aplicada a varias áreas de la biomedicina. A. Esta metodología permite la detección de linfocitos T autorreactivos que reconocen antígenos propios del paciente. Esta detección específica podría permitir la eliminación de estas células autoimmunes mediante la unión de 125I a los tetrámeros. Avances en esta dirección se han hecho en patologías como diabetes autoinmune, esclerosis múltiple y artritis reumatoidea ${ }^{40,42-44,53}$. B. Tetrámeros cargados con péptidos derivados de antígenos virales o bacterianos permiten detectar la presencia de linfocitos $\mathrm{T}$ específicos fundamentales para una respuesta inmune eficaz dirigida contra el agente infeccioso. La presencia de estas células se correlacionaría con un pronóstico positivo del paciente ${ }^{35-39}$. C. De igual forma, tetrámeros cargados con péptidos derivados de antígenos tumorales han permitido el seguimiento de pacientes vacunados contra tumores. La expansión de linfocitos T antitumorales detectada mediante el uso de tetrámeros se correlaciona con una buena respuesta inmune de los pacientes e incluso en ciertos casos con la regresión del tumor 23-34.

aplicación son las patologías autoinmunes. La identificación de linfocitos $\mathrm{T}$ específicos para antígenos propios, podńa permitir el diagnóstico y proporcionar nuevos métodos de tratamiento de enfermedades autoinmunes mediadas por linfocitos $\mathrm{T}$, tales como esclerosis múltiple, artritis reumatoidea y diabetes mellitus de tipo $1^{40-44}$. Además de esta aplicación diagnóstica, los tetrámeros de pMHC cargados con los péptidos reconocidos por los linfocitos $\mathrm{T}$ autoinmunes y conjugados con moléculas capaces de eliminar a estas células autorreactivas (como factores de complemento o ${ }^{125} \mathrm{I}$ ), podrían ser utilizados para la eliminación específica de estas células perjudiciales para el paciente. La combinación de estas aplicaciones diagnósticas y terapéuticas de los tetrámeros de pMHC podría conducir a reemplazar los actuales tratamientos sistémicos (corticoides) para la autoinmunidad y sus efectos colaterales.

La patología autoinmune en que el uso de los tetrámeros ha tenido mayor relevancia hasta el momento es la diabetes de tipo 1. Los tetrámeros de pMHC se han utilizado recientemente para la detección de linfocitos $\mathrm{T}$ autorreactivos en la diabetes mellitus de tipo 1 , tanto en humanos como en el ratón. Por medio de esta metodología se han identificado antígenos que son objeto del ataque de linfocitos $\mathrm{T}$ autorreactivos, los que incluyen a la insulina y la decarboxilasa del ácido glutámico ${ }^{45-52}$. De la misma manera los tetrámeros de pMHC se han utilizado con el objetivo de cuantificar los linfocitos $\mathrm{T}$ con especificidad para antígenos pancreáticos tanto en el modelo de ratón diabético no obeso $^{53-55}$ como en humanos ${ }^{56}$, permitiendo la caracterización de los linfocitos T autorreactivos.

Además, un estudio reciente ha demostrado la detección y cuantificación de linfocitos $\mathrm{T}$ autorreactivos en personas consideradas en riesgo de desarrollar diabetes ${ }^{56}$. De acuerdo con este estudio, los tetrámeros de pMHC podrían, en el futuro, ser utilizados con fines profilácticos para cuantifi- 
car niveles de linfocitos con potencial autoinmune, a fin de prevenir el desarrollo de la diabetes.

Comentarios finales. Los tetrámeros de pMHC también han sido utilizados para la detección de linfocitos $\mathrm{T}$ antígeno-específicos directamente en tejidos, mediante técnicas de inmuno-histoquími$\mathrm{ca}^{57}$. Esta metodología podría permitir estudiar la especificidad antigénica de los linfocitos que han infiltrado tejidos durante procesos inflamatorios. De la misma manera, se podría estudiar la especificidad de los linfocitos $\mathrm{T}$ que han infiltrado tumores. La identificación de tales antígenos podría permitir su utilización en el diseño de vacunas antitumorales.

\section{REFERENCIAS}

1. Gewurz BE, Gaudet R, Tortorella D, Wang EW, Ploegh HL, Wiley DC. Antigen presentation subverted: Structure of the human cytomegalovirus protein US2 bound to the class I molecule HLAA2. Proc Natl Acad Sci USA 2001; 98: 6794-9.

2. HAYDER H, MULBACHER A. Molecular basis of immune evasion strategies by adenoviruses. Immunol Cell Biol 1996; 74: 504-12.

3. JoHNSON WE, DESROSIERS RC. Viral persistance: HIV's strategies of immune system evasion. Annu Rev Med 2002; 53: 499-518.

4. Khong HT, Restifo NP. Natural selection of tumor variants in the generation of tumor escape» phenotypes. Nat Immunol 2002; 3: 999-1005.

5. MCSorLEY SJ, JENKINS MK. Antibody is required for protection against virulent but not attenuated Salmonella enterica serovar typhimurium. Infect Immun 2000; 68: 3344-8.

6. McSorley SJ, Cookson BT, Jenkins MK. Characterization of CD4+ T cell responses during natural infection with Salmonella typhimurium. J Immunol 2000; 164: 986-93.

7. SVAne IM, Boesen M, Engel AM. The role of cytotoxic T-lymphocytes in the prevention and immune surveillance of tumors lessons from normal and immunodeficient mice. Med Oncol 1999; 16: 223-38.

8. CARBOne JE, OHM DP. Immune dysfunction in cancer patients. Oncology 2002; 16: 11-8.

9. Tesselaar K, Arens R, Van Schindel GM, Baars PA, VAN Der VALK MA, Borst J ET aL. Lethal T cell immunodeficiency induced by chronic costimula-
El desarrollo de los tetrámeros de MHC ha significado un importante avance, tanto en el campo de la investigación en inmunología, como en entender mejor una serie de patologías en donde el sistema inmune participa activamente. Las cualidades que poseen estas moléculas han permitido conocer aspectos importantes sobre el sistema inmune, lo que en el área del tratamiento de enfermedades tan severas como el cáncer ha sido fundamental para el desarrollo de terapias efectivas. Son muchas las posibilidades que poseen los tetrámeros de MHC debido a la gran versatilidad que posee la técnica en sí, lo que abre un gran campo de investigación en el área biomédica.

tion via CD27-CD70 interactions. Nat Immunol 2003; 4: 49-54.

10. Kalergis AM. Modulation of T Cell Immunity by TCR/pMHC Dwell Time and Activating/Inhibitory Receptor Pairs on the Antigen-Presenting Cell. Curr Pharm Des 2003; 9: 233-44.

11. EISEN HN, SykULEV Y, Tsomides TJ. Antigen-specific T-cell receptors and their reactions with complexes formed by peptides with major histocompatibility complex proteins. Adv Protein Chem 1996; 49: 1-56.

12. KaIERGis AM, Nathenson SG. Antigen recognition by $\alpha ß T$ cells. Einstein Q J Biol Med 2000; 17: 56-68.

13. Davis MM, Boniface JJ, Reich Z, Lyons D, Hampl J, ARDEN B ET AL. Ligand recognition by alpha beta T cell receptors. Annu Rev Immunol 1998; 16: 52344.

14. Kalergis AM, Nathenson SG. Altered peptide ligand-mediated TCR antagonism can be modulated by a change in a single amino acid residue within the CDR3 beta of an MHC I-restricted TCR. J Immunol 2000; 165: 280-5.

15. Kalergis AM, Ono T, Wang F, Dilorenzo TP, Honda S, NATHENSON SG. Single amino acid replacements in an antigenic peptide are sufficient to alter the TCR V beta repertoire of the responding CD8+ cytotoxic lymphocyte population. J Immunol 1999; 162: 7263-70.

16. Kalergis AM, Goyarts EC, Palmieri E, Honda S, Zhang W, NATHENSON SG. A simplified procedure for the preparation of $\mathrm{MHC} /$ peptide tetramers: chemical biotinylation of an unpaired cysteine engineered at the C- terminus of MHC-I. J Immunol Methods 2000; 234: 61-70. 
17. Altman JD, Moss PA, Goulder PJ, Barouch DH, Mcheyzer-Wiwams MG, BeLl JI et al. Phenotypic analysis of antigen-specific T lymphocytes. Science 1996; 274: 94-6.

18. McMichael AJ, O'Callaghan CA. A new look at $T$ cells. J Exp Med 1998; 187: 1367-71.

19. Chien YH, Davis MM. How alpha beta T-cell receptors 'see' peptide/MHC complexes. Immunol Today 1993; 14: 597-602.

20. Davis MM, BJorKMan PJ. T-cell antigen receptor genes and T-cell recognition. Nature 1988; 334: 395-402.

21. Van Bieek GM, Nathenson SG. Peptide presentation by major histocompatibility class I molecules. Chem Immunol 1993; 57: 1-17.

22. Kalergis AM, Boucheron N, Doucey MA, Palmieri E, Goyarts EC, VeGH Z ET al. Efficient T cell activation requires an optimal dwell-time of interaction between the TCR and the pMHC complex. Nat Immunol 2001; 2: 229-34.

23. Rubio-Godoy V, Dutoit V, Rimoldi D, Lienard D, LejeUne F, SPeiser D et al. Discrepancy between ELISPOT IFN-gamma secretion and binding of A2/peptide multimers to TCR reveals interclonal dissociation of CTL effector function from TCRpeptide/MHC complexes half-life. Proc Natl Acad Sci USA 2001; 98: 10302-7.

24. Pittet MJ, Speiser DE, Lenard D, Valmori D, GuilauME P, DutorT V ET AL. Expansion and functional maturation of human tumor antigen-specific CD8+ $\mathrm{T}$ cells after vaccination with antigenic peptide. Clin Cancer Res 2001; 7: 796s-803s.

25. Kaiergis AM, Ravetch JV. Inducing tumor immunity through the selective engagement of activating Fcgamma receptors on dendritic cells. J Exp Med 2002; 195: 1653-9.

26. Sato Y, Sahara H, Tsukahara T, Kondo M, HirohasHI Y, NABETA Y ET AL. Improved generation of HLA class I/peptide tetramers. J Immunol Methods 2002; 271: 177-84.

27. Palmowski M, Salio M, Dunbar RP, Cerundolo V. The use of hLA class I tetramers to design a vaccination strategy for melanoma patients. Immunol Rev 2002; 188: 155-63.

28. Mami-Chouaib F, Echchakir H, Dorothee G, VergNon I, ChoualB S. Antitumor cytotoxic T-lymphocyte response in human lung carcinoma: identification of a tumor-associated antigen. Immunol Rev 2002; 188: 114-21.

29. Palermo B, Campanem R, Garbeul S, Mantovani $S$, Robustelu Della Cuna G, Necker A et al. Cytotoxic T-lymphocyte responses in melanoma through in vitro stimulation with the Melan-A peptide analogue A27L: a qualitative analysis. Melanoma Res 2002; 12: 491-8.

30. Wei CH, Uhun M, Masucci MG, LevitsKy V. Tetramer binding and secretion of interferon-gamma in response to antigenic stimulation are compatible with a range of affinities of MHC:TCR interaction and distinct programs of cytotoxic T-lymphocyte activation. Hum Immunol 2002; 63: 821-33.

31. Mandruzzato S, Rossi E, Bernardi F, Tosello V, Macino B, BAsso G ET AL. Large and dissimilar repertoire of Melan-A/MART-1-specific CTL in metastatic lesions and blood of a melanoma patient. J Immunol 2002; 169: 4017-24.

32. Sato Y, Nabeta Y, Tsukahara T, Hirohashi $Y$, Syunsui $\mathrm{R}$, MAEDA A ET AL. Detection and induction of CTLS specific for SYT-SSX-derived peptides in HLAA24(+) patients with synovial sarcoma. J Immunol 2002; 169: 1611-8.

33. Echchakir H, Dorothee G, Vergnon I, Menez J, Chouaib S, Mami-Chouaib F. Cytotoxic T lymphocytes directed against a tumor-specific mutated antigen display similar HLA tetramer binding but distinct functional avidity and tissue distribution. Proc Natl Acad Sci USA 2002; 99: 9358-93.

34. Keilholz U, Weber J, Finke JH, Gabrilovich DI, Kast WM, DISIS ML ET AL. Immunologic monitoring of cancer vaccine therapy: results of a workshop sponsored by the Society for Biological Therapy. J Immunother 2002; 25: 97-138.

35. Wedemeyer $\mathrm{H}, \mathrm{He} \mathrm{XS}$, Nascimbeni M, Davis AR, GREenBerG HB, HoOfNagle JH ET al. Impaired effector function of hepatitis $C$ virus-specific CD8+ T cells in chronic hepatitis $\mathrm{C}$ virus infection. J Immunol 2002; 169: 3447-58.

36. He XS, Rehermann B, Boisvert J, Mumm J, Maecker HT, ROEDERER M ET AL. Direct functional analysis of epitope-specific CD8+ $\mathrm{T}$ cells in peripheral blood. Viral Immunol 2001; 14: 59-69.

37. He XS, Rehermann B, López-Labrador FX, Boisvert J, Cheung R, Mumm J et al. Quantitative analysis of hepatitis C virus-specific CD8(+) T cells in peripheral blood and liver using peptide-MHC tetramers. Proc Natl Acad Sci USA 1999; 96: 5692-7.

38. Engstrand M, Tournay C, Peyrat MA, Eriksson BM, WADSTROM J, WIRGART BZ ET AL. Characterization of CMVpp65-specific CD8+ T lymphocytes using MHC tetramers in kidney transplant patients and healthy participants. Transplantation 2000; 69: 2243-50. 
39. Gea-Banacloche JC, Migueles SA, Martino L, ShuPERT WL, McNeil AC, SabBaghian MS et al. Maintenance of large numbers of virus-specific CD8+ T cells in HIV infected progressors and long term nonprogressors. J Immunol 2000; 165: 1082-92.

40. Kuwana M, Medsger TA JR, Wright TM. Highly restricted TCR-alpha beta usage by autoreactive human $\mathrm{T}$ cell clones specific for DNA topoisomerase I: recognition of an immunodominant epitope. J Immunol 1997; 158: 485-91.

41. Amrani A, Verdaguer J, Serra P, Tafuro S, Tan R, SANTAMARía P. Progression of autoimmune diabetes driven by avidity maturation of a T-cell population. Nature 2000; 406: 739-42.

42. Dilorenzo TP, Graser RT, Ono T, Christianson GJ, Chapman HD, Roopenian DC et aL. Major histocompatibility complex class I restricted $\mathrm{T}$ cells are required for all but the end stages of diabetes development in nonobese diabetic mice and use a prevalent $\mathrm{T}$ cell receptor alpha chain gene rearrangement. Proc Natl Acad Sci USA 1998; 95: 12538-43.

43. Sun D, Whitaker JN, Huang Z, Lu D, Coleclough C, WeKerLe $\mathrm{H}$ et al. Myelin antigen specific CD8+ $\mathrm{T}$ cells are encephalitogenic and produce severe disease in C57BL/ 6 mice. J Immunol 2001; 166: 7579-87.

44. Kotzin BL, Falta MT, Crawford F, Rosloniec EF, BiL $\mathrm{J}$, MARRACK P ET AL. Use of soluble peptide DR4 tetramers to detect synovial $\mathrm{T}$ cells specific for cartilage antigens in patients with rheumatoid arthritis. Proc Natl Acad Sci USA 2000; 97: 291-6.

45. MASTeler E, Bluestone J. Immunotherapy of insulin dependent diabetes mellitus. Curr Opin Immunol 2002; 14: 652-9.

46. Casares S, Brumeanu TD. Insights into the pathogenesis of type 1 diabetes: a hint for novel immunospecific therapies. Curr Mol Med 2001; 1: 357-78.

47. Casares S, Bona CA, Brumeanu TD. Modulation of CD4 $\mathrm{T}$ cell function by soluble MHC II-peptide chimeras. Int Rev Immunol 2001; 20: 547-73.

48. Casares S, Hurtado A, McEvoy RC, Sarukhan A, Von BoeHmer H, BRumeanu TD. Down regulation of diabetogenic $\mathrm{CD} 4+\mathrm{T}$ cells by a soluble dimeric peptide MHC class II chimera. Nat Immunol 2002; 3: 383-91.

49. Wong FS, Moustakas AK, Wen L, Papadopoulos GK, JANEWAY CA JR. Analysis of structure and function relationships of an autoantigenic peptide of insu- lin bound to $\mathrm{H}-2 \mathrm{~K}(\mathrm{~d})$ that stimulates CD8 $\mathrm{T}$ cells in insulin dependent diabetes mellitus. Proc Natl Acad Sci USA 2002; 99: 5551-6.

50. Wong FS, JanewaY CA JR. Insulin dependent diabetes mellitus and its animal models. Curr Opin Immunol 1999; 11: 643-7.

51. Wong FS, Janeway CA JR. The role of CD4 vs CD8 T cells in IDDM. J Autoimmun 1999; 13: 290-5.

52. Wong FS, Karttunen J, Dumont C, Wen L, Visintin I, PiLP IM ET AL. Identification of an MHC class Irestricted autoantigen in type 1 diabetes by screening an organ specific cDNA library. Nat Med 1999; 5: 1026-31.

53. Amrani A, Verdaguer J, Serra P, Tafuro S, Tan R, SANTAMARía P. Progression of autoimmune diabetes driven by avidity maturation of a $\mathrm{T}$ cell population. Nature 2000; 406: 739-42.

54. Amrani A, Serra P, Yamanouchi J, Trudeau JD, Tan R, Eшотт JF ET AL. Expansion of the antigenic repertoire of a single $\mathrm{T}$ cell receptor upon $\mathrm{T}$ cell activation. J Immunol 2001; 167: 655-66.

55. Lu CP, Jiang K, Wu CH, Lee WH, Lin WJ. Detection of glutamic acid decarboxylase activated $\mathrm{T}$ cells with I-Ag7 tetramers. Proc Natl Acad Sci USA 2000; 97: 14596-601.

56. Reijonen H, Novak EJ, Kochik S, Heninger A, Lu AW, Kwok WW ET AL. Detection of GAD65-specific T-cells by major histocompatibility complex class II tetramers in type 1 diabetic patients and at risk subjects. Diabetes 2002; 51: 1375-82.

57. Skinner PJ, Daniels MA, Schmidt CS, Jameson SC, HAASE AT. Cutting edge: In situ tetramer staining of antigen-specific $\mathrm{T}$ cells in tissues. J Immunol 2000; 165: 613-7.

58. Garboczi DN, Ghosh P, Utz U, Fan QR, Biddison WE, WIIEY DC. Structure of the complex between human T-cell receptor, viral peptide and HLA-A2. Nature 1996; 384: 134-41.

59. García KC, Degano M, Pease LR, Huang M, PeterSON PA, Teyton L ET aL. Structural basis of plasticity in $\mathrm{T}$ cell receptor recognition of a self peptide MHC antigen. Science 1998; 279: 1166-72.

60. García KC, Degano M, Stanfield RL, Brunmark A, Jackson MR, Peterson PA et al. An alpha beta T cell receptor structure at $2.5 \mathrm{~A}$ and its orientation in the TCR-MHC complex. Science 1996; 274: 209-19.

Agradecimientos

A la Fundación Helen Hay Whitney, por su generoso apoyo. 